\title{
City development opportunities
}

\author{
Xinhua Jiang \\ North China Electric Power University Baoding, Baoding 071000, China \\ 1747634287@qq.com@163.com
}

\begin{abstract}
The purpose of this paper is to improve the development of the city, here, the two cities as a case description. Firstly, an optimal plan for both cities over the next decade, which maximizes the benefits under environmental carrying capacity, is proposed. Combining the local situation and our metric, Multi-objective programming model is built. Making a thorough inquiry, we draw a conclusion that Fargo should pay most attention to environmental coordination while as for Jinggangshan, economic prosperity should be a priority. Meanwhile, this plan can not only achieve expected growth rates but also bring more economic opportunities of both cities, which verifies its stability and applicability.
\end{abstract}

Keywords: Multi-objective programming model, environmental coordination, economic prosperity

\section{Introduction}

Smart growth is an urban planning theory that originated in 1990's as a means to curb continued urban sprawl and reduce the loss of farmland surrounding urban centers. The ten principles for smart growth are ${ }^{[3]}$

- Mix land uses

- Take advantage of compact building design

- Create a range of housing opportunities and choices

- Create walkable neighborhoods

- Foster distinctive, attractive communities with a strong sense of place

- Preserve open space, farmland, natural beauty, and critical environmental areas

- Strengthen and direct development towards existing communities

- Provide a variety of transportation choices

- Make development decisions predictable, fair, and cost effective

- Encourage community and stakeholder collaboration in development decisions

These broad principles must be tailored to a community's unique needs to be effective. Thus, any measure of success must incorporate the demographics, growth needs, and geographical conditions of a city as well as the goal to adhere to the three E's.

\section{Multi-objective programming model}

\subsection{Some definitions}

- Minimum standards

When a city of criteria index is less than 20, we believe that the development of the city index is seriously uncoordinated, should give priority to optimize the index to make it less than 40 .

\section{- Input intensity}

The input intensity indicates development planning of a city in a certain aspect. And the input intensity is satisfied:

\section{- Expansion capacity}

$$
\sum_{i=1}^{5} \beta_{i}=1
$$

\section{- Indicator growth}

$$
\tilde{M}_{i}=M_{\text {imax }}-M_{i}
$$


According to the actual situation we can predict, the greater the room for development of a city is, the greater the effectiveness of the same input is. So we boldly think:

$$
\tilde{M}_{i}=M_{\text {imax }}-M_{i}
$$

\subsection{Urban Planning and its components}

We construct mathematical programming model to give reasonable plan.

Objective function:

$$
\left\{\begin{array}{l}
\max \left(\sum_{i=1}^{5} \omega_{i} K_{i}^{(1)}\right) \\
\min \left(\sum_{i=1}^{5} \sum_{j=1}^{5}\left(K_{i}^{(1)}-K_{j}^{(1)}\right)^{2}\right)
\end{array}\right.
$$

Restrictions:

$$
\left\{\begin{array}{l}
K_{i}^{(1)}=K_{i}+\beta_{i}\left(100-K_{i}\right) \\
\sum_{i=1}^{5} \beta_{i}=1 \\
K_{i} \geq 20
\end{array}\right.
$$

Using Matlab, solution can be obtained:

$$
\left\{\begin{array}{l}
\beta_{1}=[0.16,0.23,0.37,0.08,0.16] \\
\beta_{2}=[0.41,0.27,0.11,0.15,0.06]
\end{array}\right.
$$

\subsection{0ur plan for population increasing}

So you can get the direction of the two cities into energy, investment efforts were $\beta_{1}, \beta_{2}$. According to the results above, we can draw the conclusion that for Fargo, the largest indicators of the input level is environmental enforceability. The smallest investment intensity is economical prosperity and geographical conditions. Fargo's unique geographical location influences economic development, which in line with Fargo facing the problem of environmental. The task now is to develop environmentally enforceable concept.

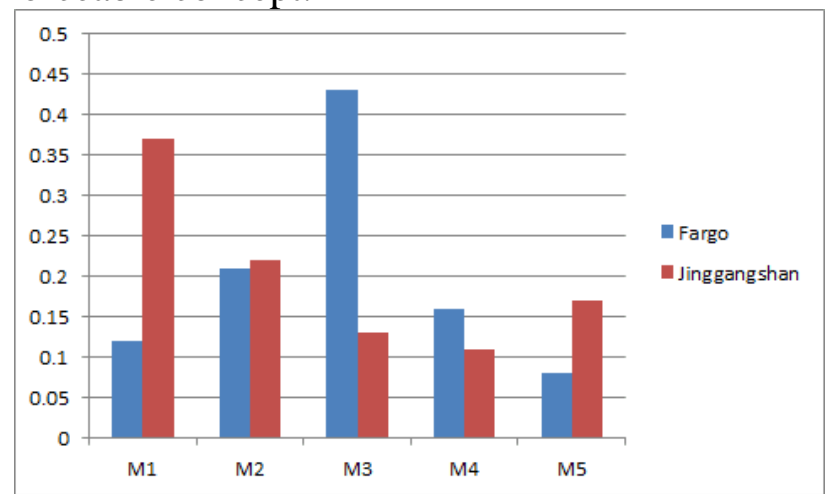

Figure 1. The weight of indicators

From Figure 5, we can get that For Jinggangshan, the largest input intensity is economic development and social equity. Jinggangshan economic prosperity and this situation have great relationship. Due to lack of economic development and economic development in the city, the weight of smart growth can be drawn, such development plan meets the expected development goals. 


\section{Further Discussion}

\subsection{Rank the individual initiatives}

Also using our metric, rank the individual initiatives within your redesigned smart growth plan as the most potential to the least potential. According to the metric of Task 1 and formula, by calculating the potential of development

\subsection{Compare and contrast the initiatives and their ranking}

According to the relevant indicators,by calculating the potential of development, compare and contrast the initiatives and their ranking between the two cities as below:

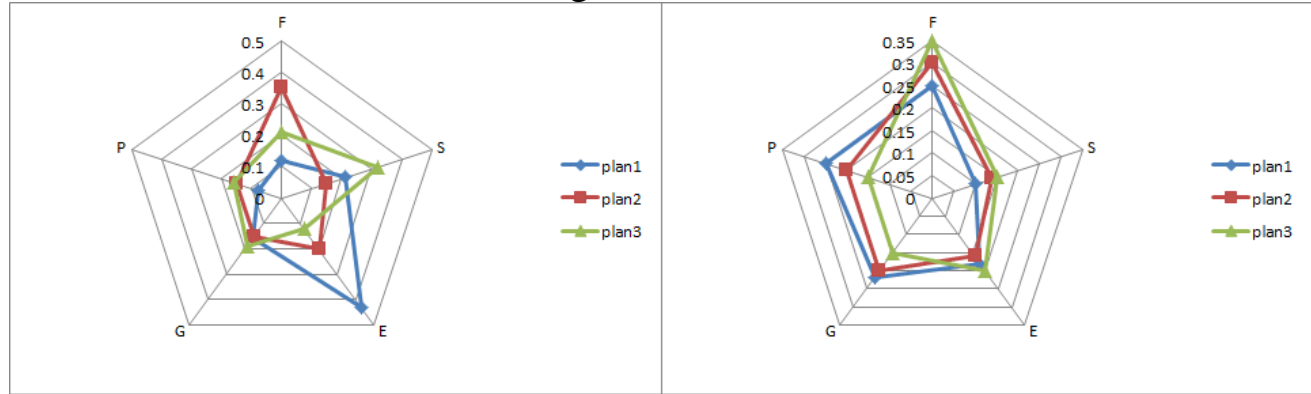

Figure 2. The development potential of the two cities

The left is the Fargo while the right is the Jinggangshan. For Fargo, plan 1 is the best solution, which is A. For Jinggangshan, plan 3 is the best solution, which is B. It can be seen that Fargo solution is better than Jinggangshan.

Through ranking and selecting initiatives, we know that Fargo should invest more in environmental development and social resources allocation, while Jinggangshan should emphasize the importance of economic development.

\subsection{Results \& analysis}

In order to account for other factors effect of population, we define Population Bottleneck Effect. We set the bottleneck effect threshold:

$$
\gamma=\frac{P}{M i}
$$

In order to ensure adequate space for development, the relevant information can be obtained. When $\gamma<0.6$, the development space meets the population growth. When the population increases, it will promote the smart development of the city. When $\gamma>0.6$, the development of the city bogs down. As $\gamma>1.5$, urban development is hampered.

Therefore, according to multi-objective programming model, we can get the following figure: 


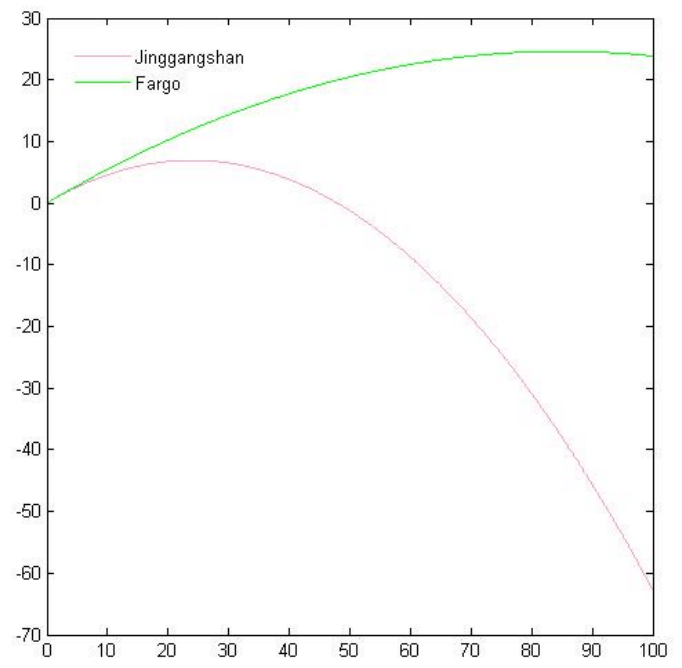

Figure 3. Results of population increasing

We focus on the effect of population growth on our planning. It is obvious that appropriate population takes part in promoting the various level indicators. Conversely, excess population will hinder the development of society.

According to the analysis above, for Fargo, the growth of the population has small effect on smart growth, while for Jinggangshan, population growth has led to a decline in urban smart development, which also confirmed that the need for limiting population planning is urgent. Therefore, we determine threshold. If the city reaches it, there will be a series of contradictions. To solve the problem of excess population growth, we revise our plan by estimating the relationship between these variables of indicators

\section{References}

[1] Smart Growth: Improving lives by improving communities. https://smartgrowthamerica.org/ [2]https://en.wikipedia.org/wiki/Smart_growth

[3] Xuhui. 14/5000 The Influence of Population Increase on China 's Economic Developmen[J]. Reform \& Opening, 2014, (9): 04-05

[4] Beijing:Higher Education Press, 2006. 226-227

Chencai. Review and Prospect of Smart City Development in 2012-2013[J]. Modern Science \& Technology of Telecommunications, 2013, (1): 28-32 